"The Media Covers Up a Lot of Things": Watchdog Ideals Meet Folk Theories of Journalism

Journalism Studies

\author{
Ruth Palmer, Corresponding Author \\ Assistant Professor of Communication, IE University \\ ruth.palmer@ie.edu
}

Benjamin Toff

Assistant Professor of Journalism and Mass Communication, University of Minnesota

Rasmus Kleis Nielsen

Professor of Political Communication and Director of the Reuters Institute for the Study of Journalism, University of Oxford

Funding: This work was supported by Google UK as part of the Google News Initiative through the Digital News Project grant held by the Reuters Institute for the Study of Journalism at the University of Oxford. 


\begin{abstract}
The idealized view of the press as an institution that operates independently from private and political interests and tries to hold power to account is central to many journalists' selfconception and extensive academic scholarship on news. Yet surveys find significant numbers of citizens reject such views about the role of news in society. This article draws on in-depth interviews with a strategic sample of 83 news avoiders in Spain and the UK to investigate "folk theories" about the relationship between news and politics. Instead of believing in the watchdog ideal, many saw the news media as, at best, irrelevant and, at worst, actively complicit with a distant and self-serving political and economic establishment. Instead of bringing important subjects to light, many saw the news as actively covering them up. The difference between professional and scholarly theories that stress the watchdog role on the one hand, and folk theories where this notion is completely absent on the other, highlights the specific cultural challenge journalism faces today. Cynicism about the role of news in society poses a problem that transcends the specific economic, political, and technological challenges that currently preoccupy many journalism professionals and institutions.
\end{abstract}

Keywords: News avoidance, news consumption, watchdog journalism, political efficacy, indepth interviews, qualitative audience research 


\section{"The media covers up a lot of things": Watchdog ideals meet folk theories of journalism}

The press-as-a-watchdog ideal is central to many journalists' professional identities and extensive academic scholarship on news. The ideal casts journalism as a heroic institution, independent from private and political interests, that informs the public about important issues and holds power to account. At least in some countries and some incarnations, journalism may approximate such ideals. Yet surveys in many places with free and diverse news media find that majorities reject the notion that news media monitor and scrutinize powerful people and businesses (Newman, Fletcher, Kalogeropoulos, \& Nielsen, 2019). In the U.S., for example, 73\% say they believe journalists should serve as watchdogs, but only three-in-ten believe they get it "about right" while the remainder believe they either go too far or not far enough (Jurkowitz \& Mitchell, 2020). Although studies have explored drivers of distrust (Strömbäck et al., 2020) and disengagement from news generally (Palmer \& Toff, 2020; Skovsgaard \& Andersen, 2019), past research has rarely considered the public's perspective on the press-as-a-watchdog ideal specifically and the complex belief systems that may contribute to skepticism about it.

In this article, we use in-depth interviews with a strategic sample of 83 news avoiders in Spain and the UK to understand what these watchdog-skeptical attitudes look like among audiences disengaged from daily news use. Interviews were conducted and analyzed in an inductive, bottom-up manner as part of a cross-national study of news avoidance, building on previous single-country (e.g., Edgerly, 2015, 2017; Toff \& Nielsen, 2018) and survey-based research on the subject (Newman, Fletcher, Kalogeropoulos, Levy, \& Nielsen, 2017; Strömbäck, Djerf-Pierre, \& Shehata, 2013). By focusing on what news avoiders think, feel, and believe about the relationship between journalism and politics, we identify distinct folk theories in Spain and 
the UK that contrast jarringly with the scholarly and professional consensus about how journalism does and should work.

Habitual news avoiders like those studied here occupy an extreme end of the news consumption spectrum. Many altogether lacked political interest, an important determinant of news consumption (Strömbäck et al., 2013). However, their views of journalism in general, and of the watchdog ideal in particular, are important precisely because they illustrate alternative notions about the role news plays in society from a position far outside the profession, removed from the debates that dominate among the relatively privileged groups operating in or near it.

Indeed, we found that interviewees almost never drew on the watchdog ideal. Instead, they saw news media as, at best, irrelevant and, at worst, complicit with a remote and selfinterested political and economic establishment. Many saw journalists not as bringing important subjects to light, but as covering them up. We conclude that the disconnect between professional and scholarly theories that stress the watchdog role on the one hand, and folk theories where this notion is absent on the other, highlights the specific cultural challenge journalism faces today. Cynicism about the role of news in society poses a problem that transcends the specific economic, political, and technological challenges that currently preoccupy many journalism professionals and institutions: For a watchdog to be effective, the public must not only hear its warnings but also heed them.

\section{Professional, scholarly, and folk approaches to the watchdog ideal}

As stated by the Nieman Foundation (2010), “The premise of watchdog journalism is that the press is a surrogate for the public, asking probing, penetrating questions at every level," serving as an independent counterweight to powerful interests. Such journalism benefits society in numerous ways (see Norris, 2014): it contributes to electoral accountability during political 
campaigns, managerial accountability by checking the malfeasance of corporations and industrial powers, and legal accountability through tracking the development, enactment, and application of the laws that govern society. The concept of the press-as-a-watchdog is rooted in classical liberal theories about press-state relations (Siebert, Peterson, \& Schramm, 1963), but its modern manifestation appeared during the rise of the nonpartisan press, especially in the U.S., during the early 1900s. Industrialization, mass distribution, and the adoption of shared professional norms helped the notion spread worldwide (Schudson, 2001). It is now central to many journalists' professional identities, and beliefs about its importance are widely-held among Western and nonWestern journalists alike (Hanitzsch et al, 2011). However, as Waisbord (2000) has shown, the importation of such values in some countries has often been "half-hearted" and "visible in the rhetoric of publishers more than in actual practices and content" (p. 14).

Among scholars, much has been made of the press's struggle to live up to its idealized watchdog role, both in the U.S. (e.g., Bennett, Lawrence, \& Livingston, 2008) and across varying cultures of journalism (Hanitzsch et al., 2011; Mellado \& Van Dalen, 2014). Deviations from the ideal raise concerns because research has consistently linked press freedom to reduced rates of corruption (Brunetti \& Weder, 2003; Yazaki, 2017). Despite empirical real-world disappointments, however, the watchdog ideal remains integral to much journalism scholarship. As Kuhn and Neveu have pointed out (2002, p. 4), academics are often part of what they call an “invisible agreement" with journalists and politicians based on a shared "legitimist vision" of politics and the role of journalism, a vision that is in part based on the watchdog ideal. This agreement is so strong that, according to Zelizer (2013), it has become a "naturalized part of understanding what journalism is for." Thus, when newsrooms shrink or close down, it is often the decline of the watchdog function that most worries scholars and media critics. 
There are indications, however, that the public may not share this zeal for watchdog journalism. As Poindexter, Heider, and McCombs (2006) show using survey data and Costera Meijer (2010) shows qualitatively, the public often views aggressive watchdog coverage negatively, preferring their news sources, at least at the local level, to act as "good neighbors" rather than attack those in power. Similarly, Palmer (2018) finds Americans who interact with reporters tend to view journalists as powerful people in their own right rather than as surrogates holding power to account on their behalf-more as bullies than watchdogs. These studies notwithstanding, there remains much we do not know about the public's perspectives about the watchdog ideal.

To aid in understanding these perspectives, we draw on the notion of "folk theories," originally developed in science and technology studies (e.g., Rip, 2006) and recently adopted for the study of journalism (Nielsen, 2016). We define folk theories as implicit parts of everyday life that provide ways of thinking about and guides for acting upon the world. They can be more or less explicit, they can be shared or contentious, and they can be purely speculative, based on personal experience, and/or second-hand sources (Rip, 2006). Like other theories (professional ones, scientific ones), folk theories need not form coherent wholes, cover everything, or be universally accepted. They are rooted in wider cultures, usefully conceptualized as components of what Swidler has called "toolkits" (2001)—shared "bags of tricks," or symbolic resources— from which people put together a narrower range of "strategies for action" that they then deploy to navigate everyday life. Folk theories of journalism are thus understandings of journalism that in turn shape how one engages — or does not engage — with journalism. 


\section{Previous research on news avoidance}

In many countries, including the UK and Spain, it appears that active news avoidance has recently increased (Blekesaune, Elvestad, \& Aalberg, 2012; Newman et al., 2019; Strömbäck et al., 2013). However, rates of news avoidance vary considerably depending on how it is defined. News repertoires approaches indicate that anywhere from $18 \%$ (Edgerly, 2015) to half the American population (Ksiazek, Malthouse, \& Webster, 2010) avoids news. The Reuters Institute's Digital News Report finds the percentage who say they actively avoid news "sometimes" or "often" varies between 6 and 57\% depending on the country, while between 3 and 7\% say they access news less often than "once-a-month" or "never" (Newman et al., 2017).

Previous research has likewise shown people avoid news for a variety of reasons, some unintentional (Skovsgaard \& Andersen, 2019), and some due to socialization (Edgerly, 2017) or a lack of ties to communities that reinforce the practice of using news (Palmer \& Toff, 2020). Other reasons include gendered caretaking roles and/or a lack of emotional energy to deal with news seen as excessively negative (Toff \& Palmer, 2019). When asked in surveys, news avoiders most often say they avoid news because it is too upsetting or untrustworthy (Newman et al., 2017), and frustrations with political news are one of the main reasons they find news disturbing enough to avoid (Schrøder \& Blach-Orsten, 2016). Indeed, where distrust of political institutions is high, people appear especially likely to turn away from news (Toff \& Kalogeropoulos, 2018).

As this growing literature suggests, news avoidance cannot be reduced to mere lack of trust or political sophistication. Rather it reflects a constellation of attitudes about news and the political information environment in which news operates. By investigating attitudes about news among those least likely to consume it, we seek to distill what watchdog-skeptical views look like in practice and the specific ideas about media and politics that structure them. 


\section{Methods}

We identified folk theories inductively by analyzing 83 in-depth interviews we conducted with news avoiders in the UK and Spain between 2016-2018. Participants were identified using a screener question adapted from the Reuters Institute, which defines news avoiders narrowly as people who report accessing news less often than "once-a-month" or "never" (Newman at al., 2017). ${ }^{1}$ In 2018, just $3 \%$ of Spanish and $8 \%$ of British survey respondents fit that definition (Newman, Fletcher, Kalogeropoulos, \& Nielsen, 2018).

We focus on these extreme news avoiders as a strategic sample for three reasons. First, studying news avoiders gives qualitative insight into what surveys indicate are already widelyheld watchdog-skeptical attitudes (Jurkowitz \& Mitchell, 2020; Newman, Fletcher, Kalogeropoulos, \& Nielsen, 2019). Second, extreme news avoiders offer a perspective on news from far outside the mainstream consensus in or near the profession. That consensus - the "unspoken and uncritically accepted routines, procedures, and rules of who and what make news" (Cook, 1998, p. 75-76) - helps define and sustain the legitimacy, recognized role, and perceived public value of the institution. However, journalism's viability depends not just on how journalists approach and execute their work, but also on how members of the public think and feel about journalism, including those least interested in consuming it. Third, news avoiders offer stark evidence of something that is always true of folk theories of journalism, but that is

\footnotetext{
${ }^{1}$ The survey question was adopted from previous research (Newman et al., 2017; Schrøder and Blach-Orsten, 2016). In the UK: "Typically, how often do you access news? By news we mean national, international, regional/local news and other topical events accessed via any platform (radio, TV, newspaper or online).” In Spanish: "Normalmente, ¿con qué frecuencia consulta las noticias? Por noticias nos referimos a la información nacional, internacional, regional/local y otros acontecimientos de actualidad consultados en cualquier plataforma (radio, televisión, periódicos o Internet)." Although imprecise, we use the term "news avoider" to avoid unwieldy alternatives (e.g., "extremely-low-news-consumers") and because it is increasingly widely used in the literature.
} 
easy to forget: peoples' ideas and attitudes about the news media are shaped not only by exposure to news products, but also by other influences, including second-hand information, elite rhetoric, and immersion in a particular climate of opinion about the press. Those interviewed in this study often articulated well-defined attitudes about news despite rarely or never having consumed it regularly. While it may be tempting to dismiss their ideas about journalism as unfounded, it is still essential to understand them, because folk theories shape how people engage with news irrespective of whether or not journalists and scholars consider those theories well-founded.

A comparative study allows us to examine how contextual factors shape attitudes about news in each country (Esser \& Hanitzsch, 2012; Hallin \& Mancini, 2004). We compare the UK and Spain because they provide the balance between similarity and difference necessary for fruitful comparison (Barnhurst, 2000; Sartori, 1991). Although they are both large European countries with similar political systems — bicameral parliamentary monarchies - they have different political histories and media environments. At the time we conducted interviews (November 2016-March 2017 in the UK, and October 2017-February 2018 in Spain), both countries were in the midst of political crises, with the UK reeling from its Brexit vote (June 23, 2016), and Spain from its Catalonia independence referendum (held on October 1, 2017).

With regards to their media systems, Spain continues to fit well into Hallin and Mancini's (2004) polarized pluralist category, characterized by elite-oriented newspapers, relatively low journalistic professionalism, and a high degree of political parallelism. Spain ranks first on this dimension according to Brüggemann and colleagues' framework (2014), meaning that most news outlets express a particular political orientation (see also Humanes \& Fernández Alonso, 2015). Meanwhile, the UK's media system is a modified version of Hallin and Mancini's liberal 
model, typically characterized by high levels of commercialization and journalistic professionalism, but in this case also with strong traditions of public broadcasting (as noted in Brüggemann et al., 2014) and partisan newspapers that run the gamut from elite to mass market. Spain has a popular sports and celebrity press, but no tabloids in the English mold.

To the extent possible we applied the same recruitment procedure and research design in both countries, as is recommended for comparative studies (Esser \& Hanitzsch, 2012). In both countries we used the same research firm with access to panels of difficult-to-reach individuals to recruit working- and middle-class news avoiders between the ages 18 and 49 . The final sample included 43 news avoiders in England and 40 in Spain (see supplementary online appendices for descriptions of participants and protocols).

We applied a constructivist grounded theory approach in the interview and analysis stage (Charmaz, 2014). Interviews lasted approximately one hour, were conducted primarily in participants' homes, and followed the same semi-structured interview protocol in both countries. The protocol covered participants' daily routines; media habits; personal-, community-, and national-level concerns; and attitudes toward journalists and news. Time permitting, participants were also asked to review and discuss sample news articles. We recorded, transcribed, and coded interviews for common and divergent themes, allowing study participants' perspectives to inform interviews over time as new theoretical constructs emerged.

Although individuals can embrace folk theories that are not shared by anyone else, the folk theories we highlight below were expressed by many participants and were among the most consistent patterns we identified in the coding process. Qualitative approaches like this one do not allow for statistical generalization the way a large representative sample does. However, with strategic sampling, they do allow for logical generalization (Luker, 2008). That logic underlies 
much work in journalism studies, where findings from, for example, one high income democracy are often taken to be potentially relevant for others like it. In our case, it is unlikely such consistent patterns would emerge in our sample of 83 interviews if they were not more broadly held within the population of news avoiders in these two countries, or that the consistent differences we identified by comparing across the two countries are mere coincidence. Our purpose is not to test the various causal factors that lead to news avoidance but rather to explain the folk theories we found and show how they fit into the broader narratives news avoiders used to explain their own behaviors.

The news avoiders we interviewed were skeptical about many of the functions scholars usually ascribe to journalism (Palmer \& Toff, 2020). However, in this article we focus on folk theories they embraced about how journalism functions in relation to politics. We applied an inductive approach so we could understand how interviewees themselves defined politics and its relationship to journalism. Although we asked participants to complete a self-administered survey that included questions about political attitudes and engagement at the end of each interview, the interview protocol itself was designed to avoid referencing politics in any explicit manner. In this paper we therefore focus on moments when participants specifically referred to "politics," politicians, and issues they associated fairly explicitly with those terms. One of the challenges - which also turns out to be a finding, as we discuss below — of trying to analyze news avoiders' views on the relationship between journalism and politics is that interviewees themselves often conflated politics and journalism, or switched back-and-forth between them in ways that made it difficult to know to which they were referring.

All names used below are pseudonyms, and for readability we have translated the Spanish quotes, but the originals are available in a supplementary online appendix. 


\section{News Avoiders' Folk Theories about the Relationship between Journalism and Politics}

In this section we begin by discussing two folk theories we observed in both countries:

first, the notion that there is no separating the press from politics more generally and, second, the belief that none of it matters to people's lives anyway. We then delve into the main differences we detected between the UK and Spain, which center around interviewees' views about who ultimately pulls the strings behind the news.

\section{I don't like news because I don't like politics}

If we apply a broad definition of politics to include the politics of everyday life, much of what we discussed in the interviews could be considered political—for example, many interviewees expressed strong views on issues such as crime, terrorism, immigration, or unemployment, and some were quite active in their communities. But even very engaged interviewees themselves usually did not think of their opinions or actions as political. For example, we asked Amelia why she said she had no interest in politics, since her detailed critique of the British criminal justice system seemed to suggest otherwise. She answered that, "I didn't really know that's political opinions...But I don't think it makes a difference. I really don't think anything makes a difference what anyone says because it all goes on what the people at the top say, and I think that's all that matters. I really do."

Like Amelia, most interviewees reserved the terms "politics" and "political" to describe what professional politicians do, usually at the national level, and seemingly far from daily life. They also shared Amelia's feeling of low political efficacy, as we discuss further below. Many associated politics with bickering among political professionals, or, especially in Spain, what they described as political ineptitude and corruption. Given that interviewees thought of politics in that way, it is perhaps unsurprising that nearly all of them said they were uninterested in 
politics, expressing an aversion that ranged from indifference to emphatic cynicism. The vast majority did not identify with any political party. Some had simply never paid much attention to politics, while others self-described as apolitical, or said they were fed up with the whole system, offering comments like Spaniard Manuel's concise, “All the parties are the same shit with different names."

In theory, people with an aversion to politics could value journalism for holding power to account even more than political enthusiasts, but we found no evidence of that. The lack of interest and even disdain many felt for politics seemed to bleed into their feelings about news and vice versa. In fact, far from valuing news because of its political coverage, interviewees often said that they avoided news in part because it covered politics, offering observations like Ryan's (UK) blunt, 'I hate politics. It's probably one of the reasons I don't read the news, to be honest." Like news avoiders (and news consumers) in many other studies, our interviewees felt news in general was too negative, and some specifically cited political stories as examples of news that left them feeling upset, sad, angry, and emotionally drained. Others said they avoided politics and political news in part because they found it too confusing and difficult to decipher, in some cases to such an extent that they had given up trying. For example, speaking about Brexit coverage, Gracie in the UK explained, "I spent 30 years not really paying much attention to the news. There's so much to catch up on that it blows my mind, that I don't understand what's going on. So I sort of gave up really.”

But often the line between news about politics and politics itself got so blurry it was hard to tell to which interviewees were referring, or whether they were really separable in their minds. That extended to how they talked about the workers in the two fields. Most participants in both Spain and the UK had never met a journalist, and some were not sure what journalists did, 
exactly (e.g., Amelia: “Journalists? Are they the people that write the stories?"). Some hesitated to opine about journalists for that reason, but others made clear that they were not sure where the line lay between politicians and journalists at all. For example, when asked his impressions of journalists, Ryan in the UK responded, "I don't really know a journalist. In my head, I'm going journalist, politician, I don't know." In terms of their trustworthiness, Manuel in Spain saw little difference between journalists and other "important people" like politicians, noting bluntly, "No, I don't trust that there's transparency in the news. We see so much fraud by important people, so much corruption, why wouldn't the newspapers also hide things?"

In sum, news is one of the key ways, if not the only way, most citizens get information about what politicians are doing, so a certain blurring of the line between news and politics in audiences' minds may be inevitable. But across interviews in the UK and Spain, the basic separation between the work of journalists and the figures they cover-a precondition for the press-as-watchdog ideal to function — was often, at best, less-than-evident to news avoiders.

\section{Political news doesn't affect me-and I can't affect it.}

As we explained in the previous section, interviewees mostly thought political news chronicled relentless corruption and bickering among distant politicians. Little wonder, then, that nearly everyone said they were uninterested in following politics because it "does not affect me directly." Many used that exact phrase in both Spain and the UK, and interviewees in both countries consistently expressed an acute sense of their own political inefficacy. In other words, even the few participants who said they knew politics could ultimately affect them felt they could not affect politics, so what was the point in following political news? Many made observations similar to Emily's (UK) that, when it came to politics, "Nobody can actually change it. Because at the end of the day, us little people, it doesn't count what us little people think. It's whatever 
the government decides to do. That's the important thing." As we explain further below, rather than seeing the biggest political news stories of the day-Catalonian Independence and Brexitas exceptions, interviewees often gave precisely those topics as examples of political news that was particularly irrelevant to their daily lives and that they could do nothing to change.

While some interviewees seemed resigned to feeling they could do little to influence politics, others found it frustrating — almost as though political news coverage were rubbing their noses in issues over which they had no control. Many saw avoiding political news as part of a larger strategy for managing their emotions. Rather than engage with news that would leave them feeling sad about the state of the world and frustrated about their own impotence to change it, they chose to conserve their emotional energy to focus on their own problems. For example, Paloma, a working mother in Madrid, said she preferred light entertainment in her precious free time. Of news and politics she noted, "I feel so incapable of changing anything and so frustrated about it...it's all a big cycle, isn't it? Have politicians stolen from us again? Ah! They've stolen from us again...It's always the same. The situation doesn't change. The names change, but the news is the same."

\section{They'll do anything to sell a story: Avoiding tabloid sensationalism in the UK}

In addition to the similarities described above, we found notable differences between the two countries in how interviewees perceived news and its specific failings. Many UK interviewees barely mentioned politics explicitly_a notable absence in an hour-long discussion that covered the issues that concerned them most, their daily routines, and their media habits so soon after the Brexit vote. When a few did mention Brexit, they used language like Megan did when we asked what she thought was the most important issue facing the UK. She responded, "I don't know, probably Brexit at the minute, I'd say. I'm not really big into politics." In other 
words, interviewees knew other people considered Brexit important, but they themselves mostly saw Brexit as an example of the kind of distant political issue they found uninteresting, confusing, and disconnected from daily life.

That interviewees rarely mentioned politics was consistent with their feelings of alienation from politics discussed above. But it also reflected features of the British media system and how interviewees were positioned in it. Many of the UK news avoiders did not immediately think of hard-hitting political news when they thought about news in general, and they almost never mentioned the BBC. Instead, the news outlets they most often mentioned as examples, were tabloids like the Sun, which they associated with grisly crime news, sports, and celebrity gossip — what Chelsea described as "a lot of waffle":

There's a lot of waffle in newspapers, isn't there? A lot of, so-and-so did this, with soand-so, or, so-and-so did that, so you might get the odd few important stories, especially your Sun, or whatever, newspapers, or your Daily Star, or whatever. But, a lot of it is a load rubbish, it's all gossip about celebrities, really, or scandal that people have been done, it's not necessarily all news.

With this as their default idea of what news was like, it is perhaps unsurprising that English news avoiders consistently complained that news was too sensationalistic and negative, which they saw as a symptom of a profit-hungry press. As they explained, news outlets were commercial enterprises, so they could not be trusted to present the unvarnished truth - they twisted and exaggerated as a matter of course, to "sell stories." Gracie, an antiques dealer, tellingly compared what journalists did with her own work:

When I'm selling my things at my stall you definitely say whatever you want the customer to hear. Because you're trying to sell it, because that's my job...I do have 
broken things that need to be sold. So I do tell a little lie. Well, not a little lie, but like, "Oh I bet super glue will fix that" sort of thing. The journalists are just doing the same thing. They're just interpreting this information to make a salable story.

This general impression of news coverage as massaged and sensationalized to maximize profit encompassed not only celebrity and crime news, but also political news on the occasion it came up in the discussion. Consistent with their tendency to think of journalism and politics as overlapping spheres, interviewees described politicians, too, as profit-seekers. For example, Amelia said she did not understand what the different political parties stood for, but that she assumed, "they all kind of want to do the same thing, which is get rich."

Since many interviewees saw both politicians and news organizations as aiming primarily to make money, it was often unclear who they thought was responsible for sensationalizing political stories. But they often used the term "scaremongering" to describe that particular kind of exaggeration, with Brexit as a prime example. Nicole illustrates that below. Note that it is unclear who she sees as responsible for the messages she is receivinggovernment officials or the news outlet — but the impact it had on her was simultaneously unsettling and confusing. When asked if she was paying attention to Brexit coverage, she responded:

I did watch something on BBC news, like a meeting or something and they were outlining the pros and the cons and things and I didn't really understand it and the thing that I were picking up, it was the government were forcing you to choose, yeah, they weren't telling you what would happen if we did leave and the implications, they were, it were like scaremongering a bit, so I didn't really, I felt it weren't true, if you know what I mean, like it weren't really a reliable source, like the government weren't really telling 
the truth. That's all. I watched the one programme on it.

A few interviewees took this narrative to the extreme, explaining how dark forces were deliberately hiding or twisting information to keep citizens ignorant or distracted from what powerful people were really doing. They did not distinguish clearly between the roles of government officials and journalists in this shady practice. But their accusations of "scaremongering," "manipulation," and cover-ups expressed an underlying suspicion of the news media's motives. For example, Patrick first warned that, "I'm going to sound like a conspiracy theorist," but went on to explain that he believed news and media in general were designed deliberately to keep people in an anxious state by feeding collective fears "that we live in a big, scary place and we've got no control over what happens and stuff." Caitlin, who said she knew corruption when she saw it after years on the police force, believed much of the news could not be trusted, because it was manipulated to cover up such malfeasance. She explained that a lot of news was "what the government want you to hear, the way they want you to think, and what they want you to believe. It's a lot of cover-ups as well, from what actually is going on.”

On the rare occasions when interviews turned to something akin to watchdog journalism, participants were dismissive, usually citing it as another example of the kind of news they found tedious and overly negative. Adam conceded that reporting about politicians' finances was "an important subject," but added that "I'm sick of hearing about it, cause it's been dragging on so long. Whenever you do put the news on, there's always something about MPs' expenses, so it gets boring." Jessica gave stories about politicians using government money to buy swimming pools as an example of the unnecessary, bleak news she'd like to see less of, explaining that it "put the attention on all the wrong people, rather than highlighting all the good in the world." 
Time permitting, at the end of our interviews we asked participants to read and reflect on examples of recent news stories, sometimes about politics. For those who had not yet mentioned politics, it was often the moment when they said they disliked it. One of the articles, from the BBC, concerned opposition-leader Jeremy Corbyn's finances. Though not an in-depth investigative piece, the story covered a fairly typical watchdog topic, and reactions to the article were particularly telling. For example, Nicole commented after reading it that,

I just look at it, and I just think to myself, I should be interested, because it's telling me that he's not paying enough tax. But then, I feel, deep down, whoever is writing it, are they trying to create a witch hunt against him? Why is it being written? Why is it being exposed? Also, why is it not being investigated by the proper sources? If he is tax avoiding, surely, the HMRC should be looking into this, rather than the BBC...I question why somebody has written that, what's the ulterior motive to somebody writing something like that.

Not only did interviewees appear not to value the BBC's close scrutiny of a politician's finances; if anything, some, like Nicole, saw it as inappropriate for a news outlet to pursue this kind of story. They seemed more suspicious of the news organization's motives than of the politician's. Perhaps their suspicion stemmed partly from an inclination to defend the Labour leader, but it was consistent with a broader belief, expressed throughout the interviews, that news organizations were primarily motivated by their own interests, not public service.

As we discuss further in the discussion section below, interviewees' suspicion of news media's motives, combined with their rejection of traditional news sources, might make them open to anti-journalism political rhetoric. Few of the news avoiders we met had yet embraced a populist party or figure. But at the end of each interview we asked them if they thought it was 
“important to be informed about the news." Hollie's response hints at a receptivity to political rhetoric that attacks the authority of the press as an independent institution:

Hollie: Yes, but what else I was reading on Donald Trump was, how he was saying that certain news's are fake, and when you read stuff like that, you think, if he's saying it, and he's the President of the US now, you just never know what's going on. Do you know what I mean? So, it's like, I don't know.

Interviewer: How do you make sense of all the different sources of information? Hollie: I just don't trust anything, to be honest.

\section{All the channels show a different version, so you can't trust any of them: Frustration with partisan news in Spain}

We saw the same range of general attitudes toward politics in Spain as in the UK-from indifference to dislike_— but Spaniards talked significantly more about establishment politics than English participants did, for two main reasons. First, unlike in the UK, many Spaniards expressed an active frustration with politics in their country, frequently naming "the government," "corruption," or simply "politics" when we asked what they thought was the main problem facing Spain. Second, reflecting differences in their media systems, whereas tabloids usually came to English news avoiders' minds when they reflected on news, Spaniards immediately thought of politically partisan news. As discussed above, scholars have found that Spanish news continues to show a high level of political parallelism (Brüggemann et al., 2014; Humanes \& Fernández Alonso, 2015), meaning that news outlets in both print and television tend to espouse a particular partisan view. Indeed, nearly all interviewees in Spain made a comment almost identical to Iñigo's that:

What I do see is that the journalism is there but it's manipulated. I mean, you watch a 
news broadcast on Channel One, for example, and they tell you one thing, and later you watch Telecinco, and they give it a different focus. Or if you read El Mundo it's one thing, and if you read El Pais it's another.

Like Iñigo, interviewees generally saw differences in the way the same story was being reported by different outlets as proof they were biased ("sesgados") or outright manipulated ("manipulados")—exhibit A for why you could not trust any of them. As Sofia summed it up, "All the news channels and the newspapers show information in their favor, according to their politics or their way of thinking, so in the end you'll never get a 'virgin' piece of news. They can manipulate it however they want."

To be sure, English news avoiders sometimes talked about manipulation, but among the Spanish interviewees the frustration was more pronounced, and they connected it more explicitly to political influence. Some interviewees emphasized the role played by economic interests in distorting news, but more so than the English news avoiders described above, Spaniards saw a direct link between financial and political motives. For example, Oliver, a computer programmer who said he avoided news because if he wanted fiction he would just watch Netflix, explained that it was impossible to separate political and economic influence behind Spanish news, "because everything is intertwined," with, for example, right-leaning businesses placing advertisements in right-leaning newspapers, and demanding positive coverage in exchange. He argued that,

In the end politics and economic power are always closely related. And the economic powers control the politicians, or the other way around. In general in Spain we all get mad about corruption. It bothers everyone that politicians put money in their pockets, but 
who hasn't paid for something without the value-added tax? And who hasn't done an invoice for a friend?

Oliver concludes here by referring to common ways that ordinary Spaniards technically cheat the system to save a little money or help out a friend. He connects the partisan and economic manipulation of news back to what he sees as a broader cultural problem of widespread corruption in Spain. He was not alone: many Spanish interviewees saw the political partisanship of news as an example of precisely the kind of pervasive graft that, in theory, a watchdog press should be weeding out, but that was so deeply rooted in the culture at large that it encompassed the news media as well. Notably, although most interviewees did not know any working journalists, they were hesitant to blame them for these larger forces. Instead, they imagined journalists as having very little autonomy_in Silvia's words, "poor things, just another worker" - who probably had to do whatever their bosses told them to do under economic and political pressures, just like everyone else.

The frustration Spanish participants felt about news that they perceived as distorted by powerful interests was thus just part of a broader narrative they told of frustration about corruption and ineptitude that, they argued, was endemic to the country. And, for some interviewees, Spanish citizens' own role in helping to sustain that system was the most depressing part of the whole news experience. For example, Susana, a working mother who worried about cuts to healthcare and education, was one of few interviewees who saw politics as affecting her life, albeit indirectly. She also saw news coverage of political affairs as, theoretically, an important public service. But she avoided news to avoid despair because she saw Spaniards themselves as too apathetic to take the steps necessary to fix the corruption that both dominated and distorted news content. She said news made her both angry and frustrated, 
because, 'It seems there's so much garbage and people don't do anything about it. In the end we do nothing. And so it's sad. It's shameful more than anything. So why am I going to waste my time?"

As discussed above, some British news avoiders spoke of conspiracies and cover ups, but in Spain it was a more consistent pattern. Spanish news avoiders often said that news organizations, either in cahoots with, or under pressure from, political powers intentionally concealed some issues and called attention to others to distract people from more important problems. As José explained,

I think the media covers up a lot of things - that because of ideology or whatever they cover up a lot of things so maybe you only get half the information, you never get all the information. I think they keep some things for their own benefit, because the government doesn't want it known or different people don't want it known.

As was the case with Brexit in the UK, in Spain interviewees consistently cited the biggest political news story in their country, the Catalonian independence referendum, as an example of all of these trends. Spanish interviews were conducted in Madrid, and not in Catalonia, where responses probably would have been different, but our interviewees saw Catalonian independence as an issue that got way too much news coverage, most likely, they believed, to cover up or distract from more important issues that politicians could not resolve, like unemployment, or that they would benefit from hiding, like their own malfeasance. As Silvia explained,

For example the Catalonian problem, it's been in the works for ages, and the politicians and news media are all obsessed with it. And in the end, what happens? I think they're like 'Look, we're going to focus on this because peoples' real problems-work, 
education, healthcare - in the end, we can't fix them.' And those are the things people really care about....the things that really affect you and are important, you have to look for that information your self.

\section{Discussion}

A basic recognition that news operates as a separate sphere from political power is a precondition for the credibility of the press's watchdog role. We did not find that interviewees believed that separation existed. They did not subscribe to the watchdog ideal or believe that news media actually held power to account on behalf of the public. Instead, they offered up their own alternative folk theories, which described journalism in very different terms: They saw journalism and politics as embroiled in a single system of distant elites out mainly to serve their own interests. They saw news coverage about politics as relentlessly negative and pointless, with little connection to their lives. Rather than seeing news about political officials as serving the public interest, most viewed such coverage cynically, as primarily motivated by a single-minded pursuit of profit, as in the UK, or partisan political gain, as in Spain. Ultimately, they felt more disempowered by news than empowered by it to make any meaningful intervention in politics.

In many countries, surveys reveal strong correlations between distrust toward the news media and distrust of political institutions, especially in polarized political environments (Ariely, 2015; Hanitzsch, van Dalen, \& Steindl, 2018; Tsfati \& Ariely, 2014). Our interviews with news avoiders in the UK and Spain show how some citizens themselves understand and articulate that relationship. To be sure, the folk theories held by our strategic sample of news avoiders should not be assumed to represent the general public. They are likely more acutely expressed here among individuals who see little value from news altogether. And they may be particularly pronounced in Spain and the UK, two countries where journalistic professionalism ranks 
relatively low (Brüggemann et al., 2014) and media outlets routinely feature politicians as analysts and commentators, perhaps further blurring the line between news and politics. However, surveys show widespread skepticism about the press-as-watchdog ideal across a variety of countries not limited to Spain and the UK (Newman et. al., 2019; Poindexter, Heider, \& McCombs, 2006). Understanding people who are part of this sizable (and potentially growing) minority of news avoiders is one step toward a more bottom-up, audience-driven understanding of how the public thinks about news - an important counterpoint to the ideal that often reflexively elevates journalism as a crucial guardian of liberal democracy.

News avoiders also provide a powerful reminder that folk theories of news are shaped by many forces beyond direct experience with news content. Many of our interviewees had little direct experience with news, yet they "knew" they could not trust it, or found it boring, or that it was part of a shady system intended to hide important matters from them. Our interest here is not whether these alternative folk theories are accurate or not. In terms of their consequences it frankly does not matter whether they are true or how they were formed. Folk theories provide toolkits for making sense of the world and strategies for acting in it. If people see journalism as part of a powerful establishment rather than as independently holding that establishment to account, they will engage with news accordingly. That is true whether such beliefs are primarily shaped by firsthand experience, hearsay, political rhetoric, or immersion in a negative climate of opinion about the press — or whether scholars and journalists think their beliefs are well-founded or not. No new business model, political regulation, technological innovation, or adjustment of news content will by itself address this issue. That will require paying close attention to the cultural processes, including folk theories, that help define the legitimacy, recognized role, and perceived public value of journalism. 
No doubt some journalists and journalisms should not be trusted and are not, in practice, watchdogs. However, whether or not they are deserved, watchdog-skeptical attitudes can be understood as a point of weakness in the news media's relationship to the general public. A news media that the public perceives as less trustworthy than politicians themselves, or in the same untrustworthy camp, is vulnerable to accusations by populist figures who lump the news media into a group with political and economic elites and claim for themselves the role of public defender. Indeed, our findings suggest that news avoiders could be particularly receptive to such appeals, especially if they are made through alternative media channels. Although they did not yet embrace populist movements, news avoiders we interviewed already more or less embraced that populist view of the news media.

Moreover, the continued existence of many news outlets now depends on peoples' willingness to not just consume news, but also to pay for it. For that reason it is hard to avoid concluding that news avoidance, whether due to watchdog-skeptical attitudes or for any other reason, poses a threat to the cultural, cognitive, and symbolic underpinnings of journalism. News organizations' ability to hold powerful people to account depends on audiences finding them credible. If people start to distrust news outlets' motives to such a degree that they trust politicians more, as some UK news avoiders in our study appeared to do, or if they see the news as part of a corrupt elite, as was the case for many news avoiders in Spain, the watchdog will be rendered ineffective. It is next to impossible for the press to hold powerful people to account if the public dismisses its warnings as mere noise, the barks not of watchdogs, but of lapdogs or mad dogs. 


\section{References}

Ariely, G. (2015). Trusting the press and political trust: A conditional relationship. Journal of Elections, Public Opinion and Parties, 25(3), 351-367. https://doi.org/10.1080/17457289.2014.997739

Barnhurst, K. G. (2000). Political engagement and the audience for news: Lessons from Spain. Journalism and Communication Monographs, 2(1), 5-60. https://doi.org/10.1177/152263790000200102

Bennett, W. L., Lawrence, R. G., \& Livingston, S. (2008). When the press fails: Political power and the news media from Iraq to Katrina. University of Chicago Press.

Blekesaune, A., E. Elvestad, and T. Aalberg. 2012. "Tuning out the World of News and Current Affairs-An Empirical Study of Europe's Disconnected Citizens.” European Sociological Review 28 (1): 110-126. https://doi-org.ezxy.ie.edu/10.1093/esr/jcq051

Brüggemann, M., Engesser, S., Büchel, F., Humprecht, E., \& Castro, L. (2014). Hallin and Mancini revisited: Four empirical types of Western media systems. Journal of Communication, 64(6), 1037-1065. https://doi.org/10.1111/jcom.12127

Brunetti, A., \& Weder, B. (2003). A free press is bad news for corruption. Journal of Public Economics, 87(7-8), 1801-1824. https://doi.org/10.1016/S0047-2727(01)00186-4

Charmaz, K. (2014). Constructing grounded theory. London: SAGE Publications Ltd. Cook, T. (1998). Governing with the news. Chicago: University of Chicago Press.

Costera Meijer, I. (2010). Democratizing journalism? Realizing the citizen's agenda for local news media. Journalism Studies, 11(3), 327-342. https://doi.org/10.1080/14616700903500256. 
Edgerly, S. (2015). Red media, blue media, and purple media: News repertoires in the colorful media landscape. Journal of Broadcasting \& Electronic Media, 59(1), 1-21. https://doi.org/10.1080/08838151.2014.998220

Edgerly, S. (2017). Seeking out and avoiding the news media: Young adults' proposed strategies for obtaining current events information. Mass Communication and Society, 20(3), 358377. https://doi.org/10.1080/15205436.2016.1262424

Esser, F., \& Hanitzsch, T. (2012). On the why and how of comparative inquiry in communication studies. In F. Esser \& T. Hanitzsch (Eds.), The Handbook of Comparative Communication Research (pp. 3-22). https://doi.org/10.4324/9780203149102-8

Hallin, D. C., \& Mancini, P. (2004). Comparing media systems: Three models of media and politics. Cambridge: Cambridge University Press.

Hanitzsch, T., van Dalen, A., \& Steindl, N. (2018). Caught in the nexus: A comparative and longitudinal analysis of public trust in the press. The International Journal of Press/Politics, 23(1), 3-23. https://doi.org/10.1177/1940161217740695

Hanitzsch, T., Hanusch, F., Mellado, C., Anikina, M., Berganza, R., Cangoz, I., ... \& Virginia Moreira, S. (2011). Mapping journalism cultures across nations: A comparative study of 18 countries. Journalism Studies, 12(3), 273-293. https://doi.org/10.1080/1461670X.2010.512502

Humanes, M. L., \& Fernández Alonso. (2015). News pluralism and public media in Spain. Televisión Española's regression following a change of government (2012-2013). Revista Latina de Comunicación Social, English Ed., 70, 270-287. doi:10.4185/RLCS-20151046en 
Jurkowitz, M., \& Mitchell, A. (2020). Most say journalists should be watchdogs, but views of how well they fill this role vary by party, media diet. Pew Research Center, Feb. 26. Available at https://www.journalism.org/2020/02/26/most-say-journalists-should-bewatchdogs-but-views-of-how-well-they-fill-this-role-vary-by-party-media-diet/

Ksiazek, T. B., Malthouse, E. C., \& Webster, J. G. (2010). News-seekers and Avoiders: Exploring Patterns of Total News Consumption Across Media and the Relationship to Civic Participation. Journal of Broadcasting \& Electronic Media, 54(4), 551-568. https://doi.org/10.1080/08838151.2010.519808

Kuhn, R., \& Neveu, E. (2002). Political journalism: Mapping the terrain. Political Journalism: New challenges, new practices. Kuhn and Neveu, eds. London: Routledge.

Luker, K. (2008). Salsa dancing into the social sciences. Cambridge: Harvard University Press. Mellado, C., \& Van Dalen, A. (2014). Between rhetoric and practice: Explaining the gap between role conception and performance in journalism. Journalism Studies, 15(6), 859878. https://doi.org/10.1080/1461670X.2013.838046

Nielsen, R.K. (2016). Folk theories of journalism: The many faces of a local newspaper. Journalism Studies, 17(7), 840-848. https://doi.org/10.1080/1461670X.2016.1165140

Newman, N., Fletcher, R., Kalogeropoulos, A., Levy, D., \& Nielsen, R. K. (2017). Digital news report. Oxford: Reuters Institute for the Study of Journalism. Retrieved from Reuters Institute for the Study of Journalism website: https://reutersinstitute.politics.ox.ac.uk/sites/default/files/Digital News Report 2017 $\underline{\text { web } 0 . p d f}$ 
Newman, N., Fletcher, R., Kalogeropoulos, A., \& Nielsen, R. K. (2018). Digital news report. Oxford: Reuters Institute for the Study of Journalism. Retrieved from Reuters Institute for the Study of Journalism website:http://media.digitalnewsreport.org/wpcontent/uploads/2018/06/digital-news-report-2018.pdf

Newman, N., Fletcher, R., Kalogeropoulos, A., \& Nielsen, R. K. (2019). Digital news report. Oxford: Reuters Institute for the Study of Journalism. Retrieved from Reuters Institute for the Study of Journalism website:

https://reutersinstitute.politics.ox.ac.uk/sites/default/files/201906/DNR 2019 FINAL_0.pdf

Nieman Foundation. (2010). The Nieman watchdog journalism project. Harvard University. Retrieved from http://www.niemanwatchdog.org/index.cfm?fuseaction=about.Mission Statement.

Norris, P. (2014). Watchdog journalism. In The Oxford handbook of public accountability. Oxford University Press.

Palmer, R. (2018). Becoming the News: How Ordinary People Respond to the Media Spotlight. New York: Columbia University Press.

Palmer, R., \& Toff, B. (2020). "What does it take to sustain a news habit: The role of civic duty norms and a connection to a 'news community' among news avoiders in the UK and Spain." International Journal of Communication, 14, 20. https://ijoc.org/index.php/ijoc/article/view/12252

Poindexter, P. M., Heider, D., \& McCombs, M. (2006). Watchdog or good neighbor? The public's expectations of local news. Harvard International Journal of Press/Politics, 11(1), 77-88. doi: 10.1177/1081180X05283795 
Rip, A. (2006). "Folk theories of nanotechnologists." Science as Culture, 15(4), 349-365. https://doi.org/10.1080/09505430601022676

Sartori, G. (1991). Comparing and miscomparing. Journal of Theoretical Politics, 3, 243-257. https://doi.org/10.1177/0951692891003003001

Schrøder, K. C., \& Blach-Orsten, M. (2016). The nature of news avoidance in a digital world. Oxford: Reuters Institute for the Study of Journalism. http://www.digitalnewsreport.org/essays/2016/nature-news-avoidance-digital-world/

Schudson, M. (2001). The objectivity norm in American journalism. Journalism, 2(2), 149-170. doi: $10.1177 / 146488490100200201$

Siebert, F., Peterson, T., \& Schramm, W. (1963). Four theories of the press: The authoritarian, libertarian, social responsibility, and soviet communist concepts of what the press should be and do. University of Illinois Press.

Skovsgaard, M., \& Andersen, K. (2019). Conceptualizing news avoidance: Towards a shared understanding of different causes and potential solutions. Journalism Studies. Advance online publication. https://doi.org/10.1080/1461670X.2019.1686410

Strömbäck, J., Djerf-Pierre, M., \& Shehata, A. (2013). The dynamics of political interest and news media consumption: A longitudinal perspective. International Journal of Public Opinion Research, 25(4), 414-435. https://doi.org/10.1093/ijpor/eds018

Strömbäck, J., Tsfati, Y., Boomgaarden, H., Damstra, A., Lindgren, E., Vliegenthart, R., \& Lindholm, T. (2020). News media trust and its impact on media use: toward a framework for future research. Annals of the International Communication Association, 44(2), 139156. https://doi.org/10.1080/23808985.2020.1755338

Swidler, A. (2001). Talk of love: How culture matters. Chicago: University of Chicago Press. 
Toff, B. \& Kalogeropoulos, A. (2018). "All the news that's fit to ignore: A comparative analysis of news avoidance." Annual Meeting of the European Communication Research and Education Association, Lugano, Switzerland, November 2018.

Toff, B., \& Palmer, R. (2019). Explaining the gender gap in news avoidance: "News-is-for-men" perceptions and the burdens of caretaking. Journalism Studies, 20(11), 1563-1579. https://doi.org/10.1080/1461670X.2018.1528882

Toff, B., \& Nielsen, R.K. (2018). "I just Google it”: Folk theories of distributed discovery. Journal of Communication, 68(3), 636-657. https://doi.org/10.1093/joc/jqy009

Tsfati, Y., \& Ariely, G. (2014). Individual and contextual correlates of trust in media across 44 countries. Communication Research, 41(6), 760-782. https://doi.org/10.1177/0093650213485972

Waisbord, S. (2000). Watchdog journalism in South America: News, accountability, and democracy. New York: Columbia University Press Worlds of Journalism. LMU Munich. https://worldsofjournalism.org/

Yazaki, Y. (2017). Newspapers and political accountability: evidence from Japan. Public Choice, 172(3-4), 311-331. doi: 10.1007/s11127-017-0444-x

Zelizer, B. (2013). On the shelf life of democracy in journalism scholarship. Journalism, 14(4), 459-473. doi: $\underline{10.1177 / 1464884912464179}$ 